\title{
El efecto dominó de las revueltas sociales de 2011 visto desde la prensa de referencia colombiana*
}

\author{
Ana María Córdoba Hernández ${ }^{* *}$ \\ Marcela Durán Camero ${ }^{* * *}$
}

Recibido: 2015-07-26 Enviado a pares: 2015-07-30

Aprobado por pares: 2015-08-30 Aceptado: 2015-09-04

\begin{abstract}
Resumen
Las movilizaciones de 2011, que comenzaron con la Primavera Árabe y se propagaron por el mundo entero, se convirtieron en un fenómeno mediático internacional, pues centraron parte de sus estrategias de acción en alcanzar visibilidad en los medios de comunicación.
\end{abstract}

Este trabajo, producto de una investigación, tuvo como objetivo analizar cómo fue el cubrimiento de las revueltas desde los principales diarios colombianos El Tiempo y El Espectador; conocer el framing y los recursos empleados para transmitir la información. Para ello, se seleccionaron todas las piezas periodísticas referentes a acciones de protesta alrededor del mundo, publicadas desde el 15 de diciembre de 2010 hasta la misma fecha de 2011 y se les aplicó una matriz de análisis de contenido cuantitativo y cualitativo.

Los resultados mostraron que el tratamiento dado a la información potenció la visibilidad de las manifestaciones, desde una perspectiva homogénea, presentando movimientos dispares y distantes como un fenómeno global y contagioso que traspasaba fronteras.

Palabras clave: Manifestaciones sociales 2011, Primavera Árabe, Movimientos de indignación, Framing, Efecto dominó , El Tiempo , El Espectador.

\footnotetext{
* Grupo de Investigación en Comunicación y Movimientos Sociales, Facultad de Comunicación, Universidad de La Sabana.

** Universidad de La Sabana. E-mail: ana.cordoba@unisabana.edu.co

*** Universidad de La Sabana. E-mail: marcela.duran@unisabana.edu.co
} 


\title{
The domino effect of the social uprisings of 2011 viewed from the colombian main press
}

\begin{abstract}
The demonstrations of 2011, which began with the Arab Spring and spread throughout the whole world, became an international media phenomenon, since they focused part of their action strategies on achieving visibility in the media.

This work, result of an investigation, aimed to analyze how was the coverage of the revolts from de main colombian journals El Tiempo and El Espectador; get to know how was the framing and resources used to transmit information, since they are the only two national circulation newspapers. For that, were selected all journalistic pieces concerning to actions of protest around the world, published from December 15, 2010 to the same date of 2011, and was applied a matrix analysis of quantitative and qualitative content.

The results pointed that the treatment given to information enhanced visibility of demonstrations, from a homogeneous perspective, presenting disparate and distant movements as a global and contagious phenomenon that transcends frontiers.
\end{abstract}

Key words: Social movements 2011, Arab Spring, Indignation movements, Framing, Domino effect, El Tiempo, El Espectador,. 


\section{Introducción}

"Egipto venció a la dictadura". Con este titular abría su edición el diario El Tiempo, el 12 de febrero de 2011. Una imagen de los manifestantes celebrando la caída del régimen, invadía la mitad de la primera página, con un pie de foto que rezaba: "Más que nunca, ayer la plaza Tahrir, que significa 'liberación', fue eso. La gente no quería parar de celebrar el fin de la larga era Mubarak" (El Tiempo, 2011e). En el interior la información sobre lo que ocurría en El Cairo ocupaba otras tres páginas de la edición.

La elección del medio por abrir la publicación con los acontecimientos de El Cairo era acertada; el hecho estaba dando la vuelta al mundo. Los ciudadanos de los países árabes hacían una demostración del poder de la sociedad civil, bajo la mirada atónita de las democracias occidentales. Luego de 30 años de dictadura, Hosni Mubarak dejaba su cargo tras las insistentes presiones del pueblo egipcio que, durante 18 días, se había reunido en las principales plazas del país para protestar en contra del Régimen.

Sin embargo, Mubarak era la segunda ficha del dominó. Un mes antes, el 15 de enero, El Tiempo publicaba el artículo: "Presión social tumba al gobierno de Túnez" (El Tiempo, 2011a) que se convertiría en el primero de muchos textos similares y en el presagio de todo el fenómeno revolucionario de los países árabes. Para entonces, ya había pasado un mes de levantamientos civiles, desde que Mohamed Bouazizi se prendiera fuego como protesta por las injusticias del régimen de Ben Alí. Lo que nadie esperaba era que un hecho aislado inspirara a miles de tunecinos a salir a las calles a manifestarse en contra de las precarias condiciones de vida y lograra derrocar un régimen de 23 años en el poder. La inmolación de Bouazizi había sido "un hecho simple, local, pero de consecuencias macro sistémicas inimaginables hasta ese momento" (Rabbia, 2012, pág. 117).

Después vino Egipto y a continuación, Libia. El 21 de octubre de 2011, tras la caída del gobierno en Trípoli, El Tiempo publicó una caricatura titulada "Otro que cae" (Matador, 2011), aunque, sin quitar su foco de atención del fenómeno que acaparaba todas las miradas de los colombianos: las protestas convocadas por la MANE (Mesa Amplia Nacional Estudiantil), contra la reforma a la Ley 30 de Educación, en distintas ciudades del país. Cuando en Bogotá los universitarios convocaban "cacerolazos" y "besatones" para exigir una "educación de calidad", en Libia morían cientos de personas, civiles y del gobierno, a manos de uno y de otro bando.

En un primer momento, tras la caída de Ben Alí, en Túnez, los dirigentes árabes descartaron que las revueltas pudieran llegar a sus fronteras nacionales. Algunos, como Mubarak y Al Assad, creyeron que no podrían derrumbar la solidez de sus regímenes, a los que veían como menos vulnerables a la ola democratizadora que había nacido en Túnez (Álvarez-Ossorio, 2011). Sin embargo, poco a poco, el miedo al contagio se propagó por el resto de países vecinos. A finales de año, continuaban cayendo fichas del dominó. El 23 de noviembre, el líder yemení, Alí Abdulá Saleh, firmaba en Riad su dimisión y se convertía en el cuarto mandatario depuesto por la fuerza de la población civil, como Ben Alí, Mubarak y Gadafi (Valenzuela, 2012). 
Paralelamente, otro fenómeno de protesta social, el de los "indignados", se extendía por todo el mundo. Los primeros brotes se presentaron en España; las imágenes de la Puerta de Sol, en Madrid, a partir del 15 de mayo, recordaban las que meses antes provenían de la plaza Tahrir, aunque el número de personas nunca alcanzara el de las acampadas egipcias.

Lo cierto es que el año 2011 se vio marcado por dos tipos de protestas y revueltas. De una parte, un levantamiento social con apariencia de manifestación pacífica se tomó países como España (15M), Estados Unidos (Occupy Wall Street), Chile y Colombia (MANE); y de otra, las protestas en los países árabes que se convirtieron en verdaderos enfrentamientos de distinta intensidad entre civiles y agentes del gobierno.

Con este trabajo se pretende analizar cómo se cubrieron las revueltas socio-políticas de la Primavera Árabe y los movimientos sociales de indignación, durante 2011, en los dos diarios de referencia colombianos El Tiempo y El Espectador. Para ello se plantearon los siguientes objetivos:

a. Comprobar si a través de las herramientas discursivas, los medios distinguían los ciclos de protestas, según sus diferentes características, contextos, y latitudes o si, por el contrario, los trataban como un fenómeno global.

b. Observar si lo publicado por los diarios sirvió para potenciar la sensación del efecto contagio entre los movimientos a lo largo de 2011, por la relación que hicieron de unos con otros.

c. Conocer cuáles fueron las protestas más llamativas para la prensa de referencia colombiana y qué proporción de cubrimiento se les dio a lo largo del año.

Para el análisis, se hizo un seguimiento a la edición impresa de ambos diarios entre el 15 de diciembre de 2010, desde que Mohamed Bouazizi se inmolara en Túnez y el 15 de diciembre de 2011, para abarcar el período de un año completo, del que se obtuvieron 459 piezas, tanto informativas como de opinión.

Una vez recolectada la muestra, se aplicó una matriz de análisis cualitativo y cuantitativo, como se explicará en la metodología, para identificar cuáles fueron las protestas más llamativas para los medios, cuánta relevancia dieron a cada una y si las relacionaron entre sí. Al mismo tiempo, se indagó si los diarios hacían o no distinción de los contextos, características de los movimientos y escenarios donde se desarrollaron las protestas. Por último, se trabajaron el discurso y las palabras utilizadas en los textos y que, de alguna manera, potenciaron la visibilidad y el efecto contagio que se percibía en las manifestaciones.

El interés por estudiar las protestas de 2011 surgió, también, luego de revisar la literatura académica que se ha publicado hasta el momento, y comprobar que la mayoría 
de trabajos se ha centrado en la repercusión que tuvieron las redes sociales e Internet y si gracias a ellos los colectivos lograron una mayor efectividad en la convocatoria y movilización social: Khamis (2011); Khondker (2011); Eltantawy \& Wiest (2011); Stepanova (2011); Comunello \& Anzera (2012) y Benkirane, R. (2012).

Sin embargo, muy pocos han analizado el tratamiento que ha dado la prensa escrita al fenómeno; aquí solo se encontraron cuatro investigaciones: la de Hamdy y Gomaa (2012), que analiza el Framing del levantamiento específicamente en Egipto, desde el contenido en idioma árabe de los periódicos y los anuncios de los medios sociales, durante el mes de enero de 2011, y tres investigaciones, que se centran específicamente en la prensa española: García (2011), Lafuente y Zugasti (2012) y Soria (2013). No está de más mencionar que no se encontró ningún análisis del caso específico colombiano.

\section{Marco teórico}

\subsection{El cubrimiento mediático de las protestas}

Algunos estudios, en torno a la comunicación de masas, llegan a la conclusión de que los medios pueden "deslegitimar" o "marginar" las protestas de los grupos que desafían el statu quo del sistema (Cohen, 1980; Gitlin, 1980; McLeod \& Hertog, 1992; Shoemaker, 1984). Según McLeod y Detenber (1999), las noticias sobre protestas tienden a centrarse más en el aspecto de los manifestantes, que en sus temas; en las acciones violentas, que en la denuncia o crítica social que hacen; en los enfrentamientos con las autoridades, que en los objetivos de la protesta por lo que terminan restando importancia a su eficacia.

Según McLeod (2007), el encuadre negativo de la información resalta, aún más, si se añaden otras prácticas periodísticas como la dependencia de fuentes oficiales, ya que las historias tienden a minimizar e incluso ignorar otras perspectivas que puedan desafiarlas: la invocación de la opinión pública, que hace ver a los "protestantes" como una minoría aislada que se desvía de los principios y valores compartidos por el resto de la sociedad; un cubrimiento superficial de la protesta, que carece de contexto y de explicación de las motivaciones últimas, hasta llegar a "demonizar" a los grupos identificando posibles amenazas y consecuencias negativas de sus acciones.

Este tipo de cobertura constituye lo que se denomina el "paradigma de la protesta" (Chan $\&$ Lee, 1984) que concluye que los medios, actuando como agentes de control social, terminan por apoyar el statu quo y relegar a los grupos que protestan, quienes, entre más radicales sean, según sus objetivos y tácticas, serán tratados con mayor dureza y encontrarán más obstáculos para alcanzar un papel determinante en el escenario político (Boyle et al., 2005; McLeod, 2007).

El interés mediático de los grupos de protesta entra en una situación paradójica. Los manifestantes buscan reconocimiento en la opinión pública, porque es ahí donde avivan sus demandas y alcanzan sus objetivos; sin embargo, no toda acción colectiva interesa a los medios, sino aquellas que encajan en las convenciones de lo que es una buena historia, por su contenido dramático: la magnitud del evento, el nivel de desorden y de conflicto, la 
proximidad con el medio, y el tipo de problemática que trata. De esta manera, los grupos caen en el juego mediático atrayendo a periodistas con acciones que justificarán la crítica, el rechazo y la deslegitimación de sus movilizaciones (McLeod, 2007; Boyle, et al., 2005).

Aunque varios autores coinciden en el paradigma de la protesta, (MacLeod $\&$ Hertog, 1992, 1995; Chan $\&$ Lee, 1984), otros plantean que no sería correcto generalizarlo, por las múltiples limitaciones que existen en el estudio del cubrimiento mediático de este tipo de fenómenos sociales. Los trabajos realizados hasta hoy estudian las protestas de manera segmentada, pues toman como muestra: medios, tiempos y lugares específicos, con los que no se puede llegar a conclusiones globales. A lo que habría que añadir los encuadres noticiosos que hacen los medios que, aunque intenten reflejar la realidad, no logran reflejos perfectos, ya que acentúan y exageran ciertas acciones y eventos, restando importancia a otros (McCluskey, M. et al., 2009).

Este último elemento es lo que se conoce como la teoría del framing que proporciona un punto de partida para estudiar los efectos del paradigma de protesta en la audiencia. El encuadre es una de las características más importantes de una noticia, tanto en el sentido de que provee de unas líneas guía a los periodistas en la construcción de los hechos, como en las orientaciones que da a la audiencia al momento de interpretarlos (Gamson W. A., 1992; Pan \& Kosicki, 1993).

El concepto de marco (frame) se deriva de la teoría de Goffman (1974). Para este autor, un marco es un esquema de interpretación que capacita a los individuos para ordenar sus vivencias dentro de un espacio de vida y del mundo y les permite procesar y entender nuevas informaciones. En la esfera comunicacional, Entman (1993) señala que los marcos construyen el mensaje desde la selección, exclusión, énfasis y elaboración del contenido mediático, al tiempo que identifican problemas, establecen sus causas, ofrecen juicios morales y recomiendan posibles soluciones. Asimismo, se manifiestan por la presencia o ausencia de ciertas palabras clave, frases hechas, imágenes estereotipadas, el uso de ciertas fuentes de información o el recurso a oraciones que refuerzan temáticamente ciertos hechos o juicios. En otras palabras, más allá de decirle a la audiencia en qué debe pensar, los marcos le señalan cómo debe pensar acerca de algo (Reese, 2007).

En este punto, concuerdan McLeod y Detenber (1999) al afirmar que el verdadero impacto del framing se da cuando las noticias determinan al público cómo debe entender los acontecimientos, temas y grupos que mencionan en la información. Los marcos seleccionados por los periodistas generan una respuesta cognitiva de la audiencia por la manera como representan ciertas ideas como las más sobresalientes o fácilmente accesibles para el espectador.

Los estudios sobre framing no conciben los textos de las noticias como estímulos psicológicos con significados objetivamente identificables; por el contrario, consideran dichos textos como un conjunto de recursos simbólicos organizados que interactúan con la mente de los individuos para construir un significado (Pan \& Kosicki, 1993). En definitiva, los frames necesitan constantemente de la interacción con la audiencia para ser efectivos. 
Según Pan y Kosicki (1993) el discurso periodístico, en este caso el de la prensa escrita, cuenta con muchos recursos para lograr el encuadre y estos se pueden clasificar en cuatro categorías, que corresponden a cuatro dimensiones estructurales del mismo: la estructura sintáctica, la estructura del guion, la estructura temática y la estructura retórica. Por los objetivos que persigue este trabajo se van a resaltar especialmente la primera y la última.

El nivel de la estructura sintáctica hace referencia al orden que se da a las palabras o frases dentro de una oración. En una noticia, se trata del nivel más básico en donde los frames pueden resultar casi imperceptibles. Sin embargo, la disposición de las palabras en el texto llega a tener un poder específico que funciona del mismo modo que la estructura de la pirámide invertida. Por ejemplo, la frase de un titular es lo más significativo de la información y logra activar ciertos conceptos en la mente de los lectores, por lo que lo convierte en el más poderoso recurso de framing en este nivel, seguido por el sumario, el lead y el resto del texto (Pan E Kosicki, 1993).

A medida que se va pasando a las otras dimensiones estructurales, el nivel de complejidad en la construcción de frames aumenta, hasta llegar al último grado, el de la estructura retórica, que hace referencia a las opciones estilísticas por la que se decantan los periodistas, según los efectos que desean en sus lectores. Aquí sobresalen los recursos del framing a los que hace alusión Gamson, como las metáforas, los ejemplos, las frases hechas, las representaciones y las imágenes visuales con las que se busca subrayar algún punto específico o dar más viveza a la información (Gamson E Modigliani, 1989).

\subsection{El efecto dominó de las protestas de 2011}

Las protestas que se desarrollaron durante 2011 constituyen una ola mundial de indignación que encontró en la movilización su forma de acción. Se puede afirmar, siguiendo a Della Porta y Diani (2011), que estos colectivos, de las más variadas latitudes, vieron en el levantamiento multitudinario una respuesta no-rutinizada que iba más allá de las convencionales formas de participación en las democracias representativas y con la que se abrían canales indirectos de influencia a través de la actividad de una serie de actores colectivos y de ciudadanos comunes.

Como explica Koopmans (2007), la observación de las olas de protesta como un fenómeno emergente y aparentemente espontáneo ha llevado a muchos psicólogos de masas y estudiosos de la conducta colectiva a compararlas con epidemias (acreditados por el uso de término "contagio"), pánicos o modas.

El concepto del efecto dominó ya se emplea en distintas áreas de las ciencias sociales, pero conviene recordar que nació a mediados del siglo XX, en el seno de las Relaciones Internacionales, con el Secretario de Estado norteamericano, Jhon Foster Dulles ${ }^{1}$. Las

1 El entonces presidente, Eisenhower, en la famosa rueda de prensa, del 7 de abril de 1954, respondió con las ideas de Foster a una pregunta sobre lo que podía ocurrir si Indochina caía bajo el influjo del comunismo. Si los soviéticos lograban hacerse cargo de este país, los grupos comunistas locales tendrían el estímulo y apoyo material necesario para tomar el control en Birmania, Tailandia, Malasia e Indonesia, lo que representaría un importante logro geoestratégico, ubicando el comunismo en posiciones cercanas 
palabras de Foster fueron recreadas plásticamente por el presidente Eisenhower, al compararlas con el modo como se van precipitando rápidamente las fichas de un dominó una tras otra, en cuanto se cae la primera.

En ese primer momento, se creía que el efecto contagio se daba principalmente en países que compartían características similares como la cultura, el lenguaje o la historia. Sin embargo, hoy en día, los medios al servicio de la globalización han permitido que disminuyan las barreras que impedían la efectividad del contagio. Como se ha visto a partir de 2011, las olas de protesta trascienden con más facilidad las fronteras que establecen las relaciones de poder y los modismos culturales, y se caracterizan por su capacidad de desestabilizar radicalmente las relaciones sociales dentro de la comunidad política (Koopmans, 2007).

El proceso de contagio o de difusión tiene para Koopmans (2007), retomando las ideas de Strang y Soule (1998) y de Myers (2000), dos importantes características. En primer lugar, se da únicamente a través de la comunicación desde una fuente a un adoptante, a través de redes establecidas. En el caso de las movilizaciones sociales en la era de la globalización, estos canales son los medios de comunicación, desde la prensa escrita hasta las redes sociales y los blogs en Internet. En palabras del autor, los medios de comunicación anuncian innovaciones entre grupos que no comparten vínculos sociales en absoluto y por tanto, desempeñan un papel crucial en la difusión de protestas en las democracias modernas (Koopmans, 2007).

Este planteamiento lo retoman Bennet y Segerberg (2012) cuando afirman que si nos fijamos en PPF (Put People First), en la Primavera Árabe, en los indignados, o en Occupy, observamos un sorprendente éxito en la comunicación de mensajes políticos simples que se dirigen directamente a los públicos externos utilizando tecnologías digitales comunes como Facebook o Twitter. Por ejemplo, el marco de acción ‘somos el 99 por ciento’ que surgió de las protestas Occupy estadounidenses, en 2011, atravesó el mundo rápidamente a través de historias personales y de imágenes compartidas en redes sociales.

Para Rabbia (2012) el uso masivo de Internet aceleró el llamado «efecto contagio», permitiendo no solo movilizar a las sociedades a través de su articulación y coordinación, gracias a estas herramientas, sino que también, acercó las experiencias de otros países a las realidades locales, logrando que cada país obtuviera su propia impronta.

Finalmente, Castells explica el contagio en los movimientos de indignación a lo largo de 2011 de esta manera:

Los movimientos se refieren los unos a los otros y se difunden por efecto de demostración. En España y en Grecia la referencia a Islandia y a las revoluciones árabes fue constante. En el llamamiento de Adbuster, la revista de Vancouver

a los países de la primera línea de defensa del capitalismo en la zona: Japón, Taiwán, Filipinas, Australia y Nueva Zelanda (Eisenhower, 1954). La teoría del efecto dominó, en últimas, planteaba la posibilidad de que en una determinada región la caída de uno de los Estados clave en manos del comunismo podría conducir a un efecto parecido al de las fichas de este juego y arrastrar a otros en su caída (Tovar Ruiz, 2011). 
que convocó en primer lugar a la ocupación de Wall Street el 17 de septiembre, se cita a Egipto y al 15M español como las experiencias que marcan el camino a seguir. Hay una conciencia colectiva global de estar en la misma lucha, pero anclada en críticas y reivindicaciones específicas de cada país y de cada localidad (2012, pág. 15).

\section{Metodología}

Para la selección de la muestra, se revisó la edición impresa de los diarios y se tuvo en cuenta todo tipo de contenido, tanto informativo como de opinión, escrito o gráfico, que hiciera referencia a la Primavera Árabe o a las acciones colectivas y protestas de movimientos sociales nacionales y trasnacionales de indignación: 15M, Occupy Wall Street, movimiento estudiantil en Chile y MANE Colombia, entre otros. Cabe anotar, que se dejaron de recopilar las informaciones de Libia y Siria, cuando en estos países las manifestaciones de la población civil se convirtieron en un verdadero conflicto armado. En el caso de Libia, con el ingreso de tropas de la OTAN, y en el de Siria, cuando pasaron a ser una guerra civil, que se mantiene hasta hoy.

En total, se obtuvieron 459 piezas a las que se aplicó una matriz de análisis de contenido. Cinco variables fueron de índole cuantitativa y permitieron establecer frecuencias. Los datos se convertían en números, según se observa en la siguiente tabla y se iban registrando en el programa IBM SPSS Statistics.

Tabla 1. Matriz de variables cuantitativas empleadas para el análisis de las publicaciones

\begin{tabular}{|c|c|c|}
\hline $\mathrm{N}^{\circ}$ & VARIABLE & OPCIÓN DE RESPUESTA \\
\hline 1 & Periódico & $\begin{array}{l}\text { 1. El Tiempo } \\
\text { 2. El Espectador }\end{array}$ \\
\hline 2 & Actor & $\begin{array}{l}\text { Lugar de la revuelta (protagonista de la información) } \\
\begin{array}{ll}\text { 1. EE. UU. } & \text { 10. Libia } \\
\text { 2. España } & 11 . \text { México } \\
\text { 3. Colombia } & \text { 12. UK } \\
\text { 4. Grecia } & \text { 13. Europa } \\
\text { 5. Siria } & \text { 14. América } \\
\text { 6. Egipto } & \text { 15. Oceanía } \\
\text { 7. Chile } & \text { 16. África } \\
\text { 8. Israel } & 17 . \text { Asia } \\
\text { 9. Túnez } & \end{array}\end{array}$ \\
\hline 3 & $\begin{array}{l}\text { ¿El contenido hace referencia a } \\
\text { otro movimiento? }\end{array}$ & $\begin{array}{l}\text { 1. Sí } \\
\text { 2. No }\end{array}$ \\
\hline 4 & $\begin{array}{l}\text { ¿Cuál es el movimiento o país } \\
\text { que referencia? }\end{array}$ & $\begin{array}{l}\text { 1. Primavera Árabe } \\
\text { 2. Grecia } \\
\text { 3. Indignados España } \\
\text { 4. Occupy WS } \\
\text { 5. Chile }\end{array}$ \\
\hline
\end{tabular}




\begin{tabular}{|c|c|c|}
\hline & & $\begin{array}{ll}\text { 6. } & \text { Mane Colombia } \\
\text { 7. } & \text { México (yo soy 132) } \\
\text { 8. } & \text { Otros }\end{array}$ \\
\hline 5 & $\begin{array}{l}\text { ¿Qué tipo de referencia esta- } \\
\text { blece? }\end{array}$ & $\begin{array}{l}\text { 1. Causalidad (Movimiento A, causa del movimiento } \\
\text { B) } \\
\text { 2. Consecuencia (Movimiento A, consecuencia del } \\
\text { Movimiento B) } \\
\text { 3. Hermandad (Movimiento A y B son solidarios entre } \\
\text { sí) } \\
\text { 4. Simultaneidad (Movimiento Ay B se desarrollan en } \\
\text { paralelo) }\end{array}$ \\
\hline
\end{tabular}

Fuente: elaboración propia

En esta primera base de datos, el programa SPSS permitió trabajar con las variables desde procedimientos de "frecuencias", ya que las respuestas eran categóricas o nominales. Por ejemplo, la variable Periódico tiene dos únicas categorías: El Tiempo o El Espectador. Y así las demás variables, ninguna era de procedimiento descriptivo.

Con las "frecuencias", se construyen tablas de contingencia (crosstabs) que resultan muy útiles para cruzar las variables categóricas. Por ejemplo, si se quiere saber cuántas de las piezas informativas de uno de los diarios se refirieron a otros movimientos, se genera una tabla de contingencia de 2x2 y a partir de esta observación, se crean un documento y un gráfico que se pueden guardar para el análisis. Desde esta utilidad se cruzaron todas las frecuencias entre sí, como se verá en el análisis de los resultados.

Si se observa la descripción de cada variable cuantitativa se puede afirmar que 1 (periódico) y 2 (actor) sirvieron para conocer cuáles fueron las protestas y los países a los que se dio mayor cubrimiento en ambos diarios. Mientras que la variable 3 (¿El contenido hace referencia a otro movimiento?) es la primera que se enfoca específicamente en los objetivos de esta investigación: si los medios relacionan unos acontecimientos con otros. En caso de que se diera esa relación, se pasaba a las variables 4 (¿cuál es el movimiento o país que referencia?) y 5 (¿qué tipo de referencia establece?), que abren el análisis de si el discurso de los medios potencia la sensación del efecto contagio.

Ahora bien, si el programa SPSS es útil para el trabajo con variables cuantitativas y el cruce estadístico de frecuencias, no lo es tanto para las variables cualitativas, pues solo permite el registro de números y no de palabras, por eso se decidió hacer otra base de datos en el programa Excel para estas variables, con las que se buscaba analizar directamente el discurso de los medios.

En este caso, tras registrar los datos de clasificación de la nota, la fecha y el medio, se volcaron los titulares completos de todas las notas, los protagonistas específicos a los que se hacía mención en cualquier parte del texto, siempre que se refirieran a él con un calificativo concreto, y los adjetivos textuales o conceptos empleados por el diario para 
asociar a esas personas, grupos, colectividades o países. Cabe resaltar que en el cuadro se registraron las palabras textuales de las notas.

Tabla 2. Extracto de matriz de variables cualitativas empleadas para el análisis

\begin{tabular}{|c|c|c|c|c|c|}
\hline $\begin{array}{c}\text { \# De } \\
\text { nota en la } \\
\text { muestra }\end{array}$ & Fecha & Periódico & Titular & $\begin{array}{l}\text { Protagonista } \\
\text { mencionado }\end{array}$ & $\begin{array}{c}\text { Calificativos para referirse } \\
\text { a ese protagonista }\end{array}$ \\
\hline 1 & $01 / 02 / 2011$ & El Tiempo & $\begin{array}{l}\text { Ejército: 'No va- } \\
\text { mos a atacar a } \\
\text { manifestantes' }\end{array}$ & $\begin{array}{l}\text { Manifestacio- } \\
\text { nes egipcias }\end{array}$ & $\begin{array}{l}\text { Manifestaciones /Pro- } \\
\text { testas }\end{array}$ \\
\hline 1 & $01 / 02 / 2011$ & El Tiempo & $\begin{array}{l}\text { Ejército: 'No va- } \\
\text { mos a atacar a } \\
\text { manifestantes' }\end{array}$ & $\begin{array}{l}\text { Policía egip- } \\
\text { cia }\end{array}$ & $\begin{array}{l}\text { Muy criticada por su re } \\
\text { presión de las protestas }\end{array}$ \\
\hline 2 & 07/11/2011 & El Espectador & $\begin{array}{l}\text { "Una universi- } \\
\text { dad del tamaño } \\
\text { de nuestros sue- } \\
\text { ños" }\end{array}$ & MANE & $\begin{array}{l}\text { Movimiento estudiantil } \\
\text { deslucido durante los } \\
\text { últimos años. }\end{array}$ \\
\hline 3 & 07/11/2011 & El Espectador & $\begin{array}{l}\text { Lo que está en } \\
\text { juego }\end{array}$ & MANE & Estudiantes \\
\hline 4 & $12 / 10 / 2011$ & El Espectador & $\begin{array}{l}\text { Más arrestos de } \\
\text { manifestantes } \\
\text { en EE.UU. }\end{array}$ & $\begin{array}{l}\text { Occupy Bos- } \\
\text { ton }\end{array}$ & $\begin{array}{l}\text { Manifestantes/Congre- } \\
\text { gados/Ocupaciones }\end{array}$ \\
\hline
\end{tabular}

Fuente: elaboración propia

Luego de una primera revisión completa de la muestra se delimitaron los protagonistas a seguir, según seis grupos genéricos, en la medida en que fueran presentados con adjetivos que los calificaran directa y expresamente. Aquellos que más apariciones obtuvieron, siguiendo estas indicaciones fueron:

Tabla 3. Grupos de protagonistas a los que se hizo seguimiento desde los adjetivos empleados para referirse a ellos

\begin{tabular}{|l|l|}
\hline \multicolumn{1}{|c|}{ Protagonista } & \multicolumn{1}{c|}{ Ejemplo } \\
\hline Movimientos específicos & $\begin{array}{l}\text { 15M, Primavera árabe, Anonymus, Indignados (de distintas partes del } \\
\text { mundo), Estudiantes chilenos, Occupy (de distintas ciudades de Estados } \\
\text { Unidos) y MANE }\end{array}$ \\
\hline Países & Colombia, Egipto, Yemen, Estados Unidos, España, Siria, Turquía, etc. \\
\hline Mandatarios & $\begin{array}{l}\text { Alí Abdalá Saleh, Hosni Mubarak, David Cameron, Juan Manuel Santos, } \\
\text { Barack Obama, etc. }\end{array}$ \\
\hline Gobiernos & Gobierno egipcio, gobierno libio, gobierno español, etc. \\
\hline Manifestaciones & Inglesas, italianas, chilenas, españolas, colombianas, etc. \\
\hline Fuerzas de seguridad & Policía griega, ejército libio, policía colombiana, ejército tunecino, etc. \\
\hline
\end{tabular}


Gracias a la herramienta "filtro" del Excel, se pudieron cruzar las variables y visibilizar la información relacionada en ellas. Por ejemplo: cuáles calificativos se habían utilizado para referirse a Hosni Mubarak, Egipto, MANE o Siria, ya fuera en El Tiempo, El Espectador o en ambos.

A través de estos elementos se buscaba conocer el tratamiento que daban los periódicos a la información, para comprobar si a través de las herramientas discursivas, los periódicos distinguían las protestas por sus contextos y lugares y en qué casos llegaban a fusionarlas y a tratarlas como un fenómeno global. Con este tipo de análisis se pudieron conocer los términos, conceptos y analogías recurrentes en los diarios y que fortalecían las relaciones entre los distintos actores.

En el siguiente apartado, dedicado al análisis e interpretación de los datos, se van a diferenciar los resultados según cada medio: El Espectador (EE) o El Tiempo (ET). Esto se debe, no a que se hayan encontrado especiales diferencias entre uno y otro, ya que su discurso es bastante homogéneo, sino para facilitar que el lector tenga una imagen general del comportamiento de las publicaciones.

\section{Análisis e interpretación de los resultados}

\section{1. ¿Hacia dónde miran los diarios? cantidad de piezas y protagonistas de la información}

De las 459 piezas periodísticas analizadas, 273 (59\%) fueron del periódico El Tiempo y 186 (41 \%) de El Espectador. Un resultado predecible, si se tiene en cuenta que El Tiempo maneja un formato sábana, con más dimensiones y extensión que el tabloide que utiliza El Espectador; así como por el promedio de noticias "breves" que publica cada uno y donde el primero sobrepasa ampliamente al segundo.

El número de colectivos, grupos, iniciativas, acciones y grandes movimientos que protagonizaron las revueltas de 2011 fue tal, que probablemente varios de ellos quedaron fuera del radar de la prensa colombiana. Sin embargo, entre los textos analizados a lo largo del año, se comprueba que ambos periódicos hicieron seguimiento a informaciones provenientes de los cinco continentes.

La tabla 4 muestra todos los actores mencionados por los periódicos durante el período analizado para hacer después, en el gráfico 1, un filtro de los más importantes, según la cantidad de veces y periodicidad de publicación que arrojó el análisis.

En la columna titulada 'ciudad' se hace referencia a aquellas manifestaciones que tuvieron presencia y representación en una ciudad específica. En otros casos, la respuesta es "no aplica" (NA) pues, aunque en algunos países los manifestantes se tomaran un espacio concreto, se trataba más de un levantamiento nacional: por las personas que migraban a la ciudad de convocatoria, por el apoyo que recibían de otras ciudades o porque los mismos manifestantes anunciaban que su objetivo era nacional. Por ejemplo, en Egipto la plaza Tahrir, en El Cairo, fue el epicentro de las manifestaciones, siendo que 
estas representaban los intereses de todo el país y no únicamente de la capital. El caso de Barcelona, en cambio, es considerado como un acontecimiento separado a las manifestaciones madrileñas y de otras ciudades españolas por su carácter violento y por sus demandas locales. Asimismo, en el movimiento Occupy, cada colectivo, aun presentando muchas similitudes con los demás, tiene un enfoque particular que se refleja en el nombre con el que se autodenominan: Occupy Wall Street, Occupy Boston, Occupy Washington, etc.

Tabla 4. Movimientos mencionados por los periódicos

\begin{tabular}{|c|c|c|c|c|}
\hline Región & País & Movimiento & Ciudad & Colectivos \\
\hline \multirow{10}{*}{ Mundo Árabe } & Túnez & \multirow{10}{*}{ Primavera Árabe } & \multirow{10}{*}{ NA } & \multirow{10}{*}{ NA } \\
\hline & Egipto & & & \\
\hline & Yemen & & & \\
\hline & Libia & & & \\
\hline & Siria & & & \\
\hline & Marruecos & & & \\
\hline & Jordania & & & \\
\hline & Argelia & & & \\
\hline & Bahrein & & & \\
\hline & Arabia Saudita & & & \\
\hline \multirow{9}{*}{ Europa } & \multirow{5}{*}{ España } & \multirow{5}{*}{ "Indignados" (15M) } & \multirow{3}{*}{ Madrid } & "Democracia Real Ya" \\
\hline & & & & "Juventud Sin Futuro" \\
\hline & & & & "No les Votes" \\
\hline & & & Barcelona & NA \\
\hline & & & Otros & NA \\
\hline & Italia & \multirow{3}{*}{ "Indignados" } & NA & NA \\
\hline & Grecia & & NA & NA \\
\hline & Inglaterra & & Londres & "Occupy Londres" \\
\hline & Rusia & NA & NA & NA \\
\hline \multirow{6}{*}{ América } & \multirow{3}{*}{ EE. UU. } & \multirow{3}{*}{ "Indignados" } & Nueva York & "Occupy Wall Street" \\
\hline & & & Washington DC & "Occupy Washington" \\
\hline & & & Boston & "Occupy Boston" \\
\hline & \multirow{3}{*}{ Colombia } & MANE & \multirow{3}{*}{ NA } & \multirow{3}{*}{ NA } \\
\hline & & "Indignados" & & \\
\hline & & Otros & & \\
\hline
\end{tabular}




\begin{tabular}{|l|l|l|l|l|}
\hline \multicolumn{1}{|c|}{ Región } & \multicolumn{1}{|c|}{ País } & \multicolumn{1}{c|}{ Movimiento } & \multicolumn{1}{c|}{ Ciudad } & \multicolumn{1}{c|}{ Colectivos } \\
\hline \multirow{4}{*}{ América } & Chile & $\begin{array}{l}\text { Movimiento Estu- } \\
\text { diantil }\end{array}$ & NA & NA \\
\cline { 2 - 6 } & México & $\begin{array}{l}\text { Movimiento Estu- } \\
\text { diantil }\end{array}$ & NA & "Yo soy 132" \\
\cline { 2 - 6 } & Latinoamérica & $\begin{array}{l}\text { Movimiento Estu- } \\
\text { diantil }\end{array}$ & NA & NA \\
\hline \multirow{2}{*}{ Asia } & China & NA & NA & NA \\
\cline { 2 - 6 } & Israel & "Indignados" & NA & NA \\
\hline África & Nigeria & NA & NA & NA \\
\hline Mundo & "Indignados" & NA & NA \\
\cline { 2 - 6 } & NA & NA & \\
\hline
\end{tabular}

Fuente: elaboración propia

La gráfica 1 muestra el número de artículos publicados por El Tiempo y El Espectador según cada protagonista. Ayuda a identificar cuáles fueron los movimientos con mayor presencia en los medios durante todo el año y cuántos fueron los textos publicados dónde aparecieron como protagonistas. Los datos correspondientes a 'continentes' hacen referencia al número de piezas que hablen de movimientos regionales o de algún país diferente a los mencionados en la gráfica, cuya periodicidad no fue tan significativa.

Gráfica 1: Número de artículos publicados según cada actor protagonista (se referencian según los países donde se desarrollaron las manifestaciones)

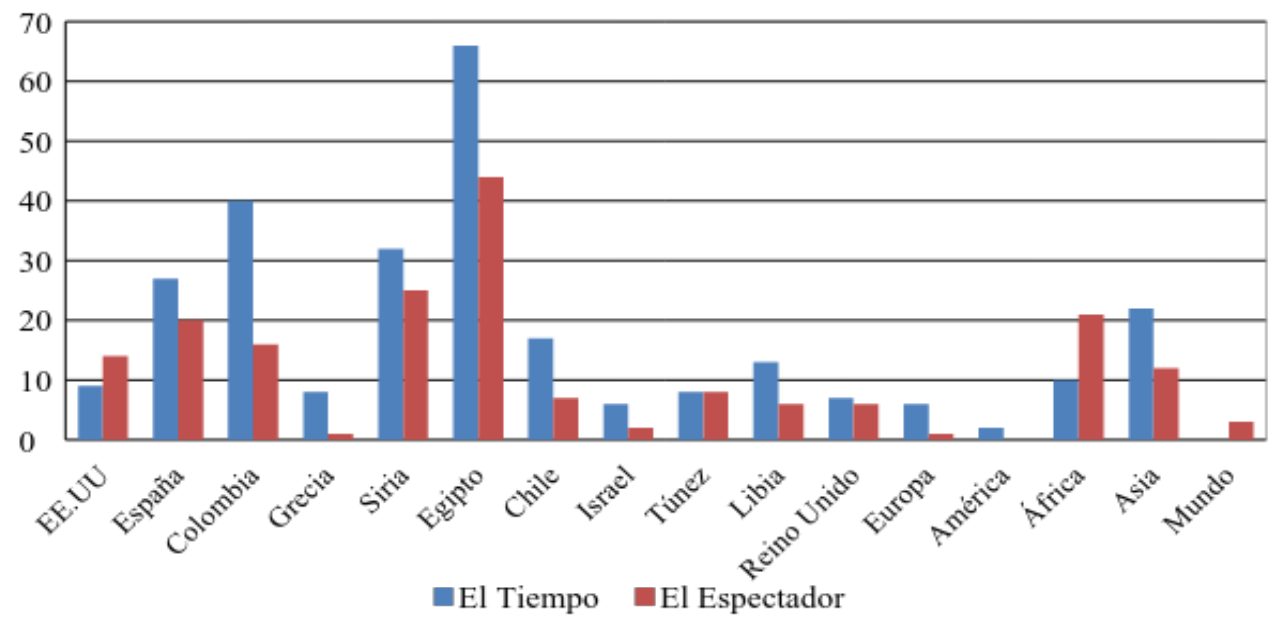

Fuente: Elaboración propia

Como se ve, las manifestaciones en Egipto encabezaron los resultados con 110 publicaciones (66, en ET y 44, en EE), con el $24 \%$ del total de la muestra, seguidas por Siria 
y Colombia con 57 y 56 textos, respectivamente, la mitad del despliegue que tuvo Egipto, dos países que merecen especial atención por lo que ha representado Siria posteriormente en estas revueltas y por la ubicación de estos medios.

El primer artículo en el que Siria acapara las miradas en El Tiempo se publica el 21 de marzo, con el titular: "Marroquíes, yemeníes y sirios claman por libertad" (Agencias, 2011). Días después en "Un mes de protestas sin precedentes", el periódico ya habla de posibles "grupos armados" en las revueltas, como un presagio de lo que estaba por venir (Reuters, 2011a). Por su parte, El Espectador empieza a dar un despliegue mayor a las manifestaciones en ese país, a partir del 25 de ese mes con "Siria, miles de voces en contra" (2011i), cuando semanas antes, las había tenido totalmente opacadas por las amenazas de una intervención internacional en el conflicto libio y las fuertes protestas en Yemen.

A pesar de haber iniciado casi simultáneamente, para El Tiempo y El Espectador las manifestaciones sirias no tuvieron, en su momento, el eco que sí tuvieron las acampadas egipcias y las protestas en Yemen y Libia. En el caso de Egipto, el número de textos se disparó con la noticia de la caída de Mubarak, el 11 de febrero, al tiempo que, la represión en Yemen y los acontecimientos en Libia evolucionaron con tal rapidez, que el número de víctimas y declaraciones internacionales captaron la atención de los rotativos colombianos. Solo durante los siguientes meses, Damasco y Al Assad recibieron mayor cubrimiento, porque las protestas, que desde un inicio fueron violentas, se convirtieron en un conflicto directo entre el régimen y la oposición, hasta evolucionar rápidamente a una guerra civil.

El caso de las noticias referentes a Colombia se entiende por el interés de los diarios en cubrir los acontecimientos propios del país. La Mesa Amplia Nacional Estudiantil (MANE) fue influyente en la política colombiana y logró detener la reforma a la educación que se pretendía hacer a la "Ley 30"2, pero no llegó a tener la relevancia internacional del movimiento estudiantil chileno.

Volviendo a la cantidad de piezas por protagonistas de la información, se encuentra el movimiento de los Indignados en España, con 47 artículos. Un resultado sorprendente si se tiene en cuenta la influencia que tendría alrededor del mundo. España pasaría a ser la cuna de un fenómeno global con presencia en todos los continentes, por convertirse en el referente de tantas otras movilizaciones. Tal es el caso del movimiento Occupy en Estados Unidos y las marchas estudiantiles en Chile, que, pese a la cercanía con Colombia, tuvieron un cubrimiento tan solo de 23 y 24 artículos, respectivamente.

Con todo, si se suman las publicaciones que hacen referencia a los países que participaron de la Primavera Árabe a lo largo de 2011, se roban el protagonismo sumando el $58,2 \%$ del total de la muestra (267 piezas) ${ }^{3}$.

2 La Ley 30 fue una iniciativa del Ministerio de Educación para hacer importantes modificaciones en el sistema de educación superior en Colombia y fue vista por miles de estudiantes como una agresión a sus derechos fundamentales. Con la presión social desatada por la MANE, el Presidente de la República, Juan Manuel Santos, decidió dar marcha atrás al proyecto el 9 de noviembre de 2011.

3 El mundo árabe está conformado por 22 países, de los cuales 15 vivieron episodios de protestas por lo que entran dentro de la "Primavera Árabe". Sin embargo, El Tiempo y El Espectador solo cubrieron los 


\subsection{Movimientos y países a los que se vuelve una y otra vez: referencias y similitudes encontradas en la muestra}

En El Espectador, 71 de los 186 artículos (38,2 \%) hicieron algún tipo de referencia entre unos y otros, mientras que en El Tiempo la cifra desciende a 56 de 273 artículos (20,5\%). La gráfica 2 muestra cómo se distribuye el número de artículos, según el movimiento referenciado, con el fin de identificar cuáles fueron los actores que recibieron más menciones en los artículos donde los protagonistas eran otros, y a cuántas piezas corresponden dichas referencias. Se ve cómo los países que hicieron parte de la Primavera Árabe fueron los más relacionados con movimientos posteriores o simultáneos: 33 veces, en El Tiempo y 44, en El Espectador.

Gráfica 2. Movimiento referenciado

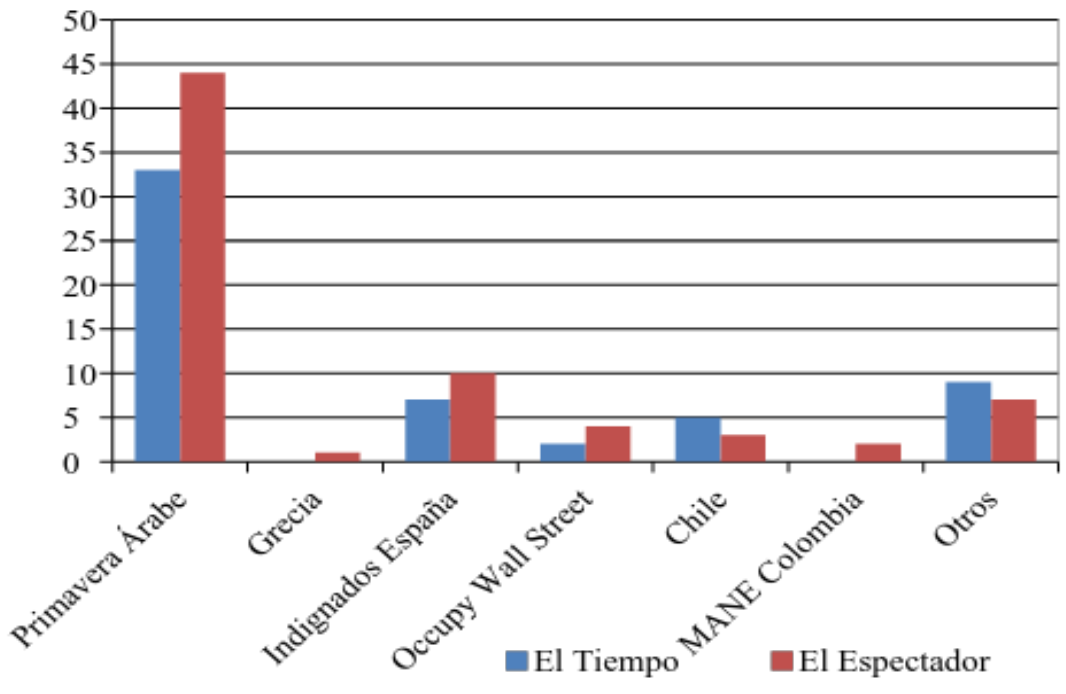

Fuente: Elaboración propia

Es llamativo el contraste de la referencia que se hace de la Primavera Árabe (77 artículos, 60,6 \%) con la del resto de protagonistas. En segundo lugar, muy por debajo de los países árabes, se encuentran las referencias al movimiento indignado en España, con 17 artículos, a quienes se relaciona con otras movilizaciones alrededor del mundo, a las que, en cierta medida, se les considera también como Indignados: los estudiantes chilenos, en 8 artículos y el movimiento Occupy Wall Street, en 6.

acontecimientos de 9 países (Siria, Marruecos, Argelia, Túnez, Libia, Egipto, Jordania, Bahréin y Yemen).

4 En la gráfica se entiende por "Primavera Árabe" tanto el fenómeno regional como cualquier país que entrara dentro de esta caracterización. Por ejemplo, un artículo cuyo tema principal fueran las manifestaciones del 15M en la Puerta del Sol (Madrid) y que en alguna parte de su desarrollo reconociera a un país Árabe como inspirador de las protestas. 
Ahora bien, ¿qué tipo de referencia existe en los textos? No es lo mismo que un movimiento adopte la identidad de otro, a que sencillamente lo apoye en sus manifestaciones. Una de las variables de la matriz que se aplicó a la muestra, indagaba sobre este aspecto, estableciendo cuatro tipos de relaciones:

a) Causalidad: cuando el movimiento A era presentado como causa del movimiento B.

b) Consecuencia: cuando se decía que el movimiento A era consecuencia de un movimiento previo B.

c) Hermandad: cuando el movimiento A y el B se presentaban como solidarios entre sí.

d) Simultaneidad: cuando A y B se presentan como movimientos que se desarrollan en paralelo.

El siguiente gráfico muestra la distribución del número de artículos que hacen referencia a otro movimiento según este tipo de relaciones.

Gráfica 3. Tipo de referencia que se hace de los movimientos entre sí

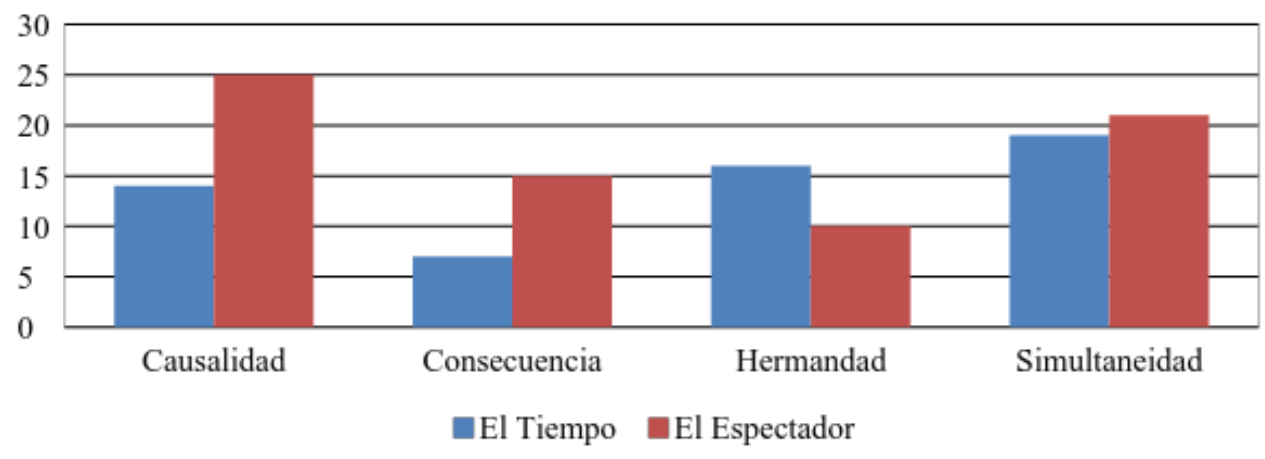

Fuente: elaboración propia

Según el gráfico, se puede afirmar que, para El Espectador, priman las relaciones de causalidad y simultaneidad, sin necesidad de tener una fuerte relación de hermandad, mientras que para El Tiempo se imponen las de hermandad y simultaneidad que muestran las manifestaciones como paralelas y solidarias entre sí.

El gráfico 4 detalla cuáles fueron los movimientos referenciados según cada tipo de relación, y el número total ${ }^{5}$ de artículos correspondientes.

5 Habiendo analizado El Tiempo y El Espectador por separado en la Gráfica 3, en esta ocasión se utiliza el resultado de la suma total de los dos periódicos por cada tipo de referencia. 
Gráfica 5. Tipo de referencia por cada actor

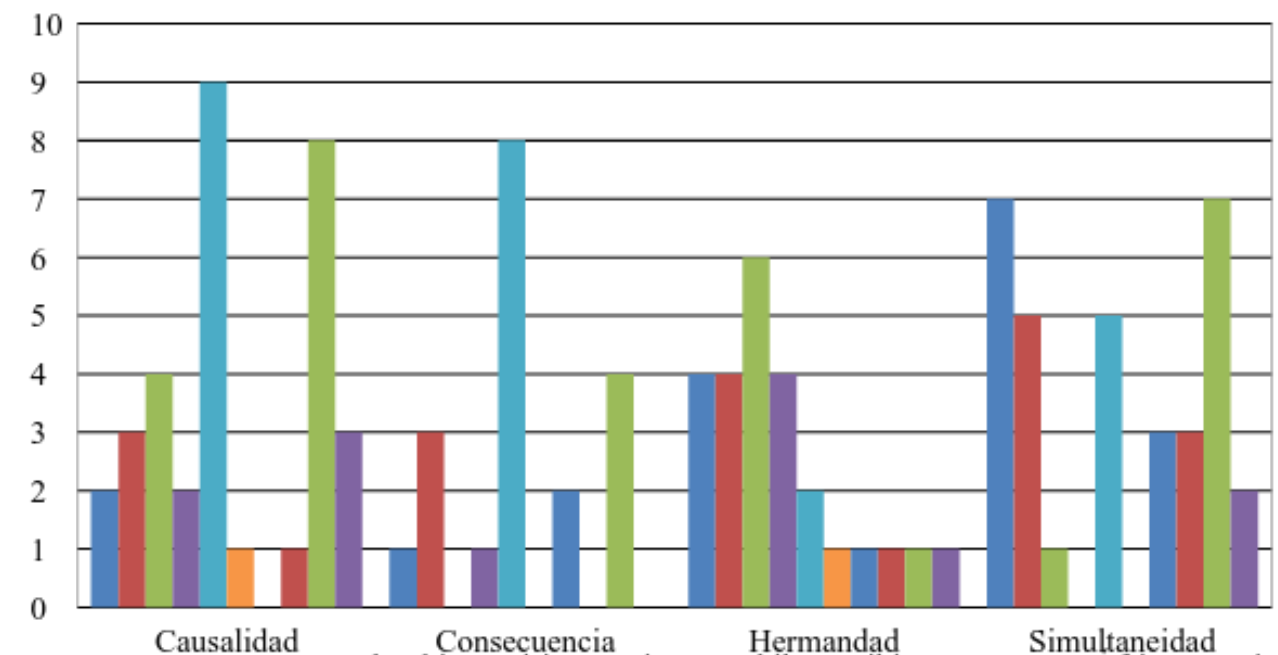

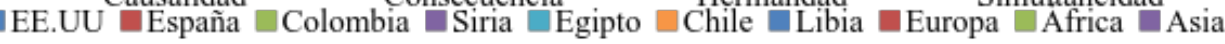

Fuente: elaboración propia

como se ve, a los movimientos indignados se les atribuyen numerosas referencias de causalidad. Al mismo tiempo, El Tiempo encuentra un mayor sentido de "hermandad" entre los movimientos de indignación en países como EE. UU., España y Colombia, que entre los manifestantes árabes entre sí.

Siria es, una vez más, un caso especial. El sentido de "hermandad" con los rebeldes sirios se da, en gran medida, por la mayor facilidad que existe de sentirse identificados y solidarios con países que sufren fuertes represiones por sus gobiernos o que están a puertas de iniciar una guerra.

Por su parte, Egipto y el resto de países del norte de África sacan la delantera en cuanto a referencias de causalidad. Si bien la plaza Tahrir no fue la cuna de la revuelta, si se convirtió en el emblema de la protesta de estos países y consolidó el efecto dominó alrededor del mundo.

En el caso de la categoría "simultaneidad", sobresalen tanto en El Tiempo, como en El Espectador, los colectivos de EE. UU. y España. Desde la aparición de Occupy Wall Street, los medios los mencionan junto con otros movimientos, sin establecer una relación más estrecha entre sí, simplemente se dan al mismo tiempo, aunque las razones y objetivos de las protestas fueran muy diferentes.

\subsection{El efecto contagio y la globalización de los movimientos sociales según los términos utilizados por los periódicos}

En este apartado conviene detenerse, en primer lugar, en el tratamiento que recibió Túnez, la cuna de todos los levantamientos, como ya se ha dicho. La ola de protestas multitudinarias en este país árabe terminó con el derrocamiento de Zine El Abidine Ben Ali, luego 
de 23 años en el poder. Se trataba, sin duda, de un acontecimiento mediático y de claro interés para la opinión pública internacional. Sin embargo, el alcance de lo ocurrido solo cobró fuerza posteriormente, cuando la revuelta saltó a otros países del norte de África.

Algunos titulares de El Espectador reconocen en Túnez el potencial que lo convertiría en la primera ficha del dominó: "Revueltas en la cuna de la Primavera Árabe" y "Túnez, el efecto dominó", son una muestra de ello (2011q; 2011c).

Introduciéndose en los textos, se descubre cómo los diarios acentúan el efecto dominó o de contagio, no solamente con titulares llamativos y dicientes, sino, también, con los calificativos que emplean para referirse a los acontecimientos posteriores como se ve en estos ejemplos: los tunecinos, "abrieron la puerta de la imposición de la voluntad popular, que ahora se esparce hacia sus vecinos" (El Espectador, 2011c); "Mohamed Bouazizi fue la chispa que habría de incendiar la pradera" (El Espectador, 2011); o bien, los acontecimientos posteriores no son más que una "ola expansiva de la revuelta tunecina" (El Tiempo, 2011b).

También se puede colegir cómo los periódicos potencian el contagio a través de las palabras que manejan para referirse a los movimientos, los países o las protestas en todo el mundo. La tabla 5 muestra algunos ejemplos que permiten identificar cómo los medios presentan las movilizaciones relacionándolas con otros movimientos o con el creciente fenómeno de indignación ya sea global o regional. En la columna de la izquierda se encuentran las palabras que se repitieron en distintas ocasiones y que sirven para acentuar la afinidad de los movimientos, y en la columna de la derecha, los ejemplos concretos y las expresiones literales de los diarios.

Tabla 5. Conceptos para presentar un efecto contagio6

\begin{tabular}{|c|l|}
\hline $\begin{array}{c}\text { Concepto/ } \\
\text { calificativo }\end{array}$ & \multicolumn{1}{|c|}{ Ejemplo } \\
\hline \multirow{4}{*}{ "También" } & Nueva York también tienen su movimiento "indignado" \\
\cline { 2 - 2 } & Jordania también protesta \\
\cline { 2 - 2 } & Colombianos también marchan hoy en Argentina \\
\cline { 2 - 2 } & Choques, también en Irán \\
\hline
\end{tabular}

6 Los ejemplos usados para demostrar los conceptos de la Tabla 5 fueron tomados de las siguientes referencias respectivamente:

También: EFE, 2011e; El Espectador, 2011b; El Tiempo, 2011k; El Espectador, 2011h

Contagio: Salgar, 2011; Bremer, 2011; Abdahllah, 2011.

Dominó: El Espectador, 2011c; Peckel, 2011a; Ospina, 2011

Extensión/Expansión: EFE, 2011a; Salgar, 2011; Peckel, 2011a; Samper, 2011

Ola: Dharmadeva, 2011; de Vasconcelos, 2011; Reuters, 2011b; El Espectador, 2011f; El Espectador, $2011 \mathrm{~g}$

Otros: Gómez, 2011; Peckel, 2011a; Bastenier, 2011. 


\begin{tabular}{|c|c|}
\hline $\begin{array}{l}\text { Concepto/ } \\
\text { calificativo }\end{array}$ & Ejemplo \\
\hline \multirow{3}{*}{ "Contagio" } & Sentimiento de indignación contagioso \\
\hline & El efecto contagio parece claro \\
\hline & Fenómeno de contagio \\
\hline \multirow{3}{*}{ "Dominó" } & Túnez, el efecto dominó \\
\hline & Un efecto dominó amenaza con cambiar el orden político árabe \\
\hline & $\begin{array}{l}\text { El efecto dominó de las manifestaciones árabes en busca de democracia en sus } \\
\text { países ahora está alcanzando el suelo europeo }\end{array}$ \\
\hline \multirow{4}{*}{$\begin{array}{l}\text { "Extensión/ } \\
\text { Expansión" }\end{array}$} & $\begin{array}{l}\text { Movimiento } 15-\mathrm{M} \text { ya se extiende a varios países (EFE, Movimiento } 15-\mathrm{M} \text { ya se } \\
\text { extiende a varios países, 2011a) }\end{array}$ \\
\hline & $\begin{array}{l}\text { Se ha expandido tan rápidamente que hoy impulsa manifestaciones en } 80 \text { (Salgar, } \\
\text { 2011) }\end{array}$ \\
\hline & $\begin{array}{l}\text { Hoguera de furia y frustración que se ha extendido vertiginosamente gracias al } \\
\text { combustible de las redes sociales (Peckel, Tsunami en Oriente Medio, 2011a) }\end{array}$ \\
\hline & $\begin{array}{l}\text { No es solo un movimiento multitudinario que se manifiesta en Madrid sino en otras } \\
\text { ciudades españolas y que se ha extendido a otros países (Samper, 2011) }\end{array}$ \\
\hline \multirow{5}{*}{ "Ola" } & La ola va más allá de Nueva York y se esparce poco a poco \\
\hline & El rugir de la ola democrática \\
\hline & Más muertos por ola de protestas \\
\hline & Oleada de protestas populares sin precedentes \\
\hline & Ola de manifestaciones \\
\hline \multirow{3}{*}{ Otros } & El movimiento crece como una bola de nieve \\
\hline & Tsunami que se extiende por todo el mundo árabe \\
\hline & Las manifestaciones son una reacción en combustión \\
\hline
\end{tabular}

Fuente: Elaboración propia

Este efecto contagio, descrito de distintas maneras y con diversos conceptos, lleva a presentar a los movimientos sociales como un fenómeno regional e incluso global, ya sea con los calificativos que textualmente globalizan las protestas o con las formas y descripciones que utilizan para abarcarlos como un todo, sin tener en cuenta aspectos que los pueden diferenciar, ni las distancias geográficas y culturales que los separan.

Concretamente, en esta tabla se muestran ejemplos de palabras que llevan al lector a tener la sensación de que se encuentra ante un fenómeno global. En la parte superior se encuentran las empleadas en titulares y en la inferior, las empleadas al interior de los textos: 
Tabla 6. Globalización del movimiento indignado

\begin{tabular}{|l|l|}
\hline \multicolumn{2}{|c|}{ TITULARES } \\
\hline \multicolumn{1}{|c|}{ El Tiempo } & \multicolumn{1}{c|}{ El Espectador } \\
\hline Más de 960 ciudades se unen a los 'indignados' & ¿Por qué la juventud mundial se está rebelando? \\
\hline Movimiento de los 'indignados' se globaliza & Un mundo de indignados \\
\hline $\begin{array}{l}\text { La voz de protesta de los indignados se hace } \\
\text { global }\end{array}$ & El mundo al revés \\
\hline Protesta global de los 'indignados' & Las protestas en el mundo \\
\hline Esta vez, la marcha de jóvenes fue continental & Marcha desde Chile hasta Colombia \\
\hline \multicolumn{2}{|c|}{ PALAS EMPEADAS EN EL INTERIOR DE LOS TEXTOS ${ }^{\circ}$} \\
\hline El Tiempo & El Espectador \\
\hline $\begin{array}{l}\text { Ya no es solo un movimiento multitudinario que } \\
\text { se manifiesta en Madrid sino en otras ciudades } \\
\text { españolas y que se ha extendido a otros países }\end{array}$ & $\begin{array}{l}\text { Hay indignados de todo el mundo que salen a } \\
\text { la calle }\end{array}$ \\
\hline $\begin{array}{l}\text { Las protestas en el mundo } \\
\begin{array}{l}\text { Las protestas parecen extenderse a otros países } \\
\text { de la región }\end{array}\end{array}$ & $\begin{array}{l}\text { Se ha expandido tan rápidamente que hoy im- } \\
\text { pulsa manifestaciones en 80 países }\end{array}$ \\
\hline $\begin{array}{l}\text { ILos inconformes]: personaje internacional del } \\
\text { año }\end{array}$ & Es también un fenómeno mundial \\
\hline $\begin{array}{l}\text { Reclamo por el cambio que no es el mismo en } \\
\text { todos los países }\end{array}$ & Protestas que se aparecen por el mundo \\
\hline
\end{tabular}

Fuente: Elaboración propia

Por la manera como se refieren a los distintos actores, los periódicos, además de reconocer al movimiento Indignado como un fenómeno global, otorgan este nombre a diversos movimientos nacionales y regionales.

Los movimientos de España, Nueva York, Washington, Boston, Colombia, Chile, Israel y Grecia son tratados en los medios como "Indignados" o que manejan "expresiones de indignación". Por ejemplo: "Nueva York también tiene su movimiento 'indignado'" (EFE, 2011e); "Los 'Indignados' cuentan con grupo de latinoamericanos" (Samper, 2011); "250 mil 'indignados' en Israel (El Tiempo, 2011g).

7 Los ejemplos de titulares usados para demostrar la globalización del movimiento indignado en los periódicos analizados (Tabla 6) fueron tomados de las siguientes referencias respectivamente:

El Tiempo: EFE, 2011f; Bloomberg, 2011; Reuters, 2011c; EFE, 2011g; El Tiempo, 2011.

El Espectador: Wolf, 2011; Salgar, 2011; El Espectador, 2011m; El Espectador, 2011j; El Espectador, $2011 \mathrm{s.}$

8 Los ejemplos de palabras empleadas al interior de los textos fueron tomados de:

El Tiempo: Samper, 2011); (Muñoz S. , 2011; Álvarez, 2011; Naim, 2011; Muñoz S. , 2011

El Espectador: Dharmadeva, 2011; El Espectador, 2011p; Salgar, 2011; El Espectador, 2011o; Tickner, 2011. 
En una entrevista realizada por Ásbel López (2011) para El Tiempo, el 23 de junio a "El 'padre' de los Indignados", Stéphane Hessel, el periodista coincide con él en cuanto a que "los 'indignados' europeos piden empleo, mientras que los 'indignados' árabes piden libertad". Es una de las pocas veces en que el medio adjudica el calificativo de "indignados" a los manifestantes de las revueltas árabes, la única zona con la que siempre se marcó la diferencia.

En general, los movimientos de indignación se pueden dividir, según lo publicado en los periódicos, en tres grupos más pequeños, pero que siguen agrupando a sus manifestantes con características identitarias comunes.

- Movimiento 15M: Cuna del movimiento Indignado y modelo de grupos posteriores. Se gestó en Madrid, tras la multitudinaria toma de la Puerta de Sol, el 15 de mayo de 2011.

Las primeras semanas, los diarios hacían referencia exclusivamente a los manifestantes madrileños, pero con el tiempo traspasan el calificativo otras ciudades como Barcelona, Valencia, Sevilla, Zaragoza y Bilbao (EFE, 2011b; EFE - AFP, 2011).

El 19 de mayo, en El Tiempo, Miguel Vázquez (2011), portavoz del movimiento 15M, define a los manifestantes como "una ciudadanía abierta e indignada"; dos días después, el medio ya se refiere a ellos como "Indignados" (EFE, 2011a), y a partir de ese momento se encuentra el calificativo en ambos diarios.

Movimiento Estudiantil. Bajo esta categoría se encuentran las marchas de estudiantes en Latinoamérica, concretamente en Chile y Colombia.

Aquí los manifestantes no son presentados como movimientos estudiantiles aislados, sino que los diarios proponen una estrecha relación entre ambos países: "Chile protesta por lo que Colombia propone" (López C., 2011); "Marcha desde Chile hasta Colombia" (El Espectador, 2011s); "[En Colombial la situación es similar a Chile" (Sarmiento, 2011).

Durante todo el cubrimiento se presenta a ambos movimientos como una serie de protestas pacíficas de inconformidad educativa que "claman por una educación de calidad" (Sarmiento, 2011).

Movimiento Occupy. Aunque nace en Nueva York con el colectivo Occupy Wall Street, con el tiempo va contagiando a otras ciudades de Estados Unidos como Boston o Washington (El Espectador, 20110) y salta a Europa, como recogen las informaciones sobre Occupy Londres.

Aunque el movimiento Occupy es considerado un movimiento Indignado, según el cubrimiento que hacen los periódicos, la violencia y vandalismo que estos manejan, en especial los manifestantes ingleses, constituyen la principal diferencia que presentan con respecto a las demás protestas occidentales.

Teniendo clara esta división de los movimientos de indignación, hay ocasiones en que no solo se relacionan entre ellos, sino que se establecen vínculos con lo ocurrido en el mundo árabe. En el artículo: "A una sola voz, Colombia pidió cese de la corrupción", El 
Tiempo (2011i) afirma que la protesta estuvo "inspirada en las recientes manifestaciones de repudio contra la corrupción en Oriente Medio, África y España". En el mismo periódico, con la caricatura titulada "Resignada inconformidad" (Papeto, 2011), se hace una analogía entre la situación política de Egipto y la de Venezuela: "Los venezolanos deberían seguir el ejemplo de los egipcios / Cuando Chávez cumpla 30 años en el poder, podrían intentar sacarlo".

Imagen 1. "Resignada inconformidad"

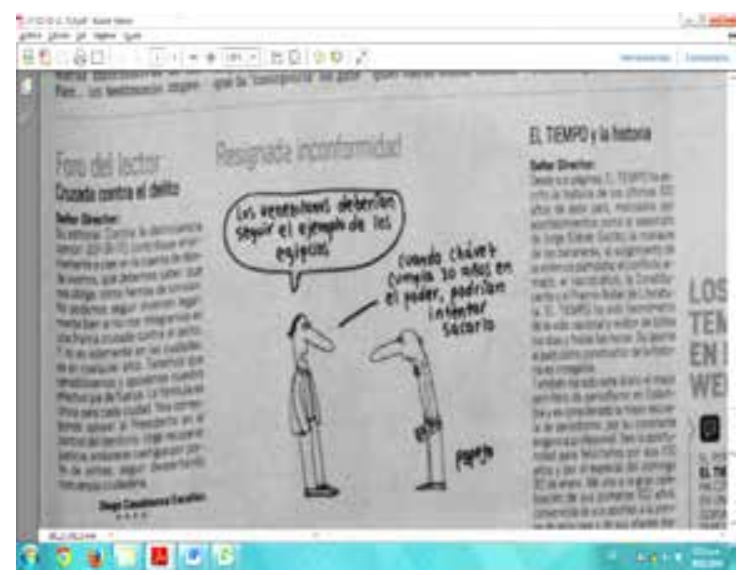

Fuente: Papeto, 2011

Ciertamente las características sociales, económicas, políticas y culturales de un país latinoamericano son muy diferentes a las de un Estado árabe; es difícil intentar comparar a Mubarak con Chávez, pero esta caricatura evidencia la confianza que iba teniendo la opinión pública internacional frente al poder que significaban los levantamientos sociales, desde principios de febrero.

A pesar de la diferencia de intereses y objetivos, varias manifestaciones alrededor del mundo recibieron, a modo de analogía con el fenómeno árabe, el calificativo de "Primavera". En este sentido se encontraron los siguientes casos, concretamente en El Espectador:

- "Primavera Árabe de Occidente", haciendo referencia del movimiento Occupy Wall Street (Pacheco, 2011)

- "Primavera China" (AFP, 2011d)

- "De la Primavera Árabe al invierno ruso" (Ortega, 2011)

- "Hay quienes presienten ya una extensión del fenómeno y empiezan a hablar de una Primavera Europea" afirmación del columnista William Ospina al referirse a las protestas vividas en España, Italia, Inglaterra, Portugal, Alemania y Bélgica en el mes de mayo (Ospina, 2011). 


\subsection{Calificativos que otorgan los diarios a los distintos protagonistas}

Analizando los adjetivos que utilizaron los diarios para referirse a los individuos presentes en las protestas, se encontró que los manifestantes árabes y los indignados tienen varias características en común y muy pocas diferencias.

La tabla 7 muestra cuáles son los calificativos más utilizados por ambos periódicos para definir y describir a los manifestantes de la Primavera Árabe y a los indignados. En los primeros, se identifica un mayor número de calificativos que no se aplicaron a los Indignados, mientras que estos últimos recibieron, en general, los mismos adjetivos que se otorgaban a los manifestantes de los países árabes.

Tabla 7. Adjetivos para referirse a los manifestantes ${ }^{9}$

\begin{tabular}{|l|l|}
\hline \multicolumn{1}{|c|}{ PRIMAVERA ÁRABE } & \multicolumn{1}{|c|}{ INDIGNADOS } \\
\hline Revolución política (democrática) & Líderes estudiantiles \\
Clamor por libertad & \\
Espontaneidad/Rapidez & \\
Protestas en contra del régimen dictatorial & \\
Son reprimidos violentamente por fuerzas de seguridad & \\
\hline Jóvenes & \\
Generalmente pacíficas & \\
Ciudadanos inconformes & \\
No se sienten representados & \\
Movimiento de resistencia & \\
Ocupaciones de espacios públicos & \\
Uso de tecnologías & \\
Sin líderes visibles & \\
Ola de protestas & \\
\hline
\end{tabular}

Fuente: elaboración propia

9 Los ejemplos de calificativos fueron tomados de varios artículos, encontrando que se repetían con frecuencia. Para la Primavera Árabe se tienen las siguientes referencias:

Revolución política/democrática: Hoyos, 2011. Clamor por libertad: Agencias, 2011. Espontaneidad/rapidez: El Espectador, 20111. Protestas en contra del régimen dictatorial: El Tiempo E EFE, 2011. Reprimidos violentamente: El Espectador, 2011 i.

Para los Indignados:

Líderes estudiantiles: El Espectador, 2011r.

Para ambos:

Jóvenes: AFP, 2011c; AFP, 2011a. Generalmente pacíficas: El Espectador, 2011q; EFE, 2011b. Ciudadanos inconformes: El Tiempo, 2011f; Papeto, 2011. No se sienten representados: Salgar, 2011; El Espectador, 2011r. Movimiento de resistencia: Barrionuevo, 2011; Bonet, 2011 Ocupaciones de espacios públicos: Salgar, 2011; El Tiempo, 2011c. Usos de tecnologías: Pacheco, 2011; Orduz, 2011. Sin líderes visibles: Peckel, 2011b. Ola de protestas: Beris, 2011; El Espectador, 2011 a.

10 Al hablar de los indignados, El Tiempo y El Espectador acostumbran a utilizar el calificativo "líderes", pero hablando de los jóvenes en general, no de una persona concreta que lidere el movimiento. En el caso de la MANE, hay artículos y entrevistas a 'voceros' que conocen plenamente las estrategias de acción del movimiento, pero no son las cabezas, ni los principales representantes del mismo. (Ej. "Desde los 70 no vivíamos algo así: vocero estudiantil" (El Tiempo, 2011j); "!Que vivan los estudiantes!" (Rueda, 2011). 
A lo largo del análisis se encuentran de modo repetitivo los mismos calificativos sin apenas diferencias de un lugar a otro. Algo parecido ocurre con la explicación de los contextos y las oportunidades políticas que hacen que surjan las revueltas.

En la columna de opinión titulada "De la utopía a la distopía" (Muñoz S., 2011), publicada por El Tiempo, el autor asegura que "a pesar de las aparentes semejanzas entre las revueltas que han sucedido este año (2011), no todas tienen la misma motivación". Para Muñoz, todos los movimientos sociales surgieron con el propósito de hacer un "reclamo por el cambio que no es el mismo en todos los países", pero esto no es tan claro en el cubrimiento que hicieron de los acontecimientos.

En cuanto a las oportunidades políticas que facilitaron la propagación de las protestas, los periódicos registran muchas similitudes de una latitud a otra, cómo se ve en la tabla 8.

Los escenarios donde se presentaron protestas de Indignados, por ser de diferentes regiones y contextos, tienen características y condiciones más dispares; mientras que los países de la Primavera Árabe se presentan con muchas semejanzas culturales y sociales.

Tabla 8. Oportunidades políticas según cada movimiento social

\begin{tabular}{|l|l|}
\hline \multicolumn{1}{|c|}{ PRIMAVERA ÁRABE ${ }^{11}$} & \multicolumn{1}{|c|}{ INDIGNADOS $^{12}$} \\
\hline - Gobernantes déspotas & - Desempleo \\
- Regímenes dictatoriales & - Deficiencias del sistema económico o del \\
- Autocracia & sistema educacional \\
- Violadores de derechos humanos & - Escasez y altos costos de vivienda \\
- Viejos dirigentes & - Falta de crecimiento y disparidad económica \\
- Restringen libertades & - Programas de austeridad \\
- No hay representación política & \\
- Represión policiaca & \\
- Desempleo juvenil & \\
- Disfrazadas de democracia & \\
-Injusticia, corrupción, desigualdad y pobreza & \\
- Altos precios en los alimentos & \\
\hline
\end{tabular}

Fuente: Elaboración propia

11 Los calificativos utilizados para definir las oportunidades políticas de la Primavera Árabe fueron tomados, entre otras, de las siguientes referencias respectivamente:

- Slackman, 2011; Pérez, 2011; Bremer, 2011; El Espectador, 2011e; Wolf, 2011; Peckel, 2011b

- Salgar, 2011; El Espectador, 2011i; Seligson, 2011; Muñoz A. , 2011; Ibídem; Plá, 2011.

12 Las referencias de los calificativos otorgados a las oportunidades políticas de los Indignados fueron, respectivamente:

Brat, 2011; Gaviria, 2011; EFE, 2011c; Moffett \& Pica, 2011; AFP, 2011b. 
Si bien, en ambos casos el sistema económico, el desempleo y la austeridad son una constante, la Primavera Árabe se destacó por su lucha contra el régimen o contra el gobernante que buscaban derrocar a cualquier precio.

Sin embargo, los Indignados se identificaron por buscar reformas en las políticas implementadas por el Estado, mas no en derrocar gobernantes. Es ahí donde radica la mayor diferencia entre ambas oportunidades: la democracia que, aunque algunos colectivos de los Indignados veían con desconfianza (Ospina, 2011), estaba presente en Occidente, mientras en Oriente se iba forjando como el mayor ideal a alcanzar.

\section{Conclusiones}

El cubrimiento que hicieron $\mathrm{El}$ Tiempo y El Espectador a las manifestaciones sociales que tuvieron lugar durante todo 2011 se puede dividir en dos grandes categorías: la Primavera Árabe y los movimientos de Indignados. De la primera se puede afirmar que, aunque obtuvo el mayor número de artículos de la muestra (58,2\%), los diarios no llegaron a abarcar todos los países que presentaron revueltas; solo informaron sobre 9, de los 15 Estados implicados. A pesar de lo anterior, los diarios decidieron agruparlos bajo un mismo paraguas, el de Estados árabes, sin hacer distinción de contextos económicos o sociopolíticos, y utilizando las mismas figuras y calificativos para referirse a ellos a lo largo del año.

Con el segundo grupo pasa algo similar; aunque hubo manifestaciones de Indignados en todos los continentes, los diarios se centran en los más representativos: el 15M de España, cuna del fenómeno global; el movimiento Occupy, originario de Nueva York y el movimiento estudiantil, con representantes en Chile y Colombia, fundamentalmente. Para este grupo, la homogeneidad con que los presentan es aún más notoria, si se tienen en cuenta las diferencias en cuanto a ubicación geográfica, hechos que motivan la protesta y condicionantes sociopolíticos en que se desarrolla.

Al hacer referencia a otros movimientos, de distintas partes del mundo, los diarios colombianos analizados reconocieron que las diversas manifestaciones en 2011 terminaron por relacionarse en algún momento entre sí y las presentaron con una misma identidad, según se tratara de los dos grandes movimientos: Primavera Árabe e Indignados. Solo los diferenciaron en el interior con algunos factores mínimos según las manifestaciones y oportunidades políticas; pero se hizo más hincapié en sus similitudes hasta presentarlos como un fenómeno global. Esto se agudizó con el empleo de palabras como: 'también', 'contagio', 'dominó, 'expansión' y 'ola', entre otras.

El frame analizado hace eco a los recursos periodísticos propuestos por Pan y Kosicki (1993). En el cubrimiento realizado por los medios, se presenta claramente una estructura sintáctica del encuadre al hacer uso de los titulares como herramienta para presentar las protestas como un fenómeno global y resaltar el efecto contagio. De igual forma, los calificativos utilizados para describir las manifestaciones y sus contextos, así como el uso de determinados conceptos que connotan un alcance transnacional, permite identificar una estructura retórica dirigida a presentarlas con una identidad compartida. 
En el cubrimiento de las protestas que se dieron durante todo 2011 alrededor del mundo, se encontró una importante desproporción de las revueltas del mundo árabe, seguido por las manifestaciones en España, con relación a los demás movimientos del mundo. Esta tendencia se dio, en primer lugar, y sin desconocer la magnitud de las acampadas de Madrid, por el carácter "pacífico" del movimiento de los Indignados, que pudo llegar a ser monótono y a convertirse en algo corriente, sin presentar la espectacularidad de las imágenes de manifestaciones violentas y llamativas, como sí se pudo presenciar en algunos países árabes.

Asimismo, las manifestaciones globales de Indignados no tuvieron, para El Tiempo y El Espectador, el mismo protagonismo de las protestas árabes dada la dificultad para medir el alcance de los resultados políticos y sociales de sus demandas. La imagen de miles de personas acampadas en las principales capitales del mundo exigiendo una serie de reivindicaciones sociales llegó a convertirse en corriente y, aunque no era su objetivo, no presentaba la espectacularidad del derrocamiento de dictadores y gobiernos.

Esto demuestra que, en el caso del cubrimiento colombiano de las protestas mundiales de 2011, el paradigma de la protesta se aplica en el sentido de que los medios dieron mayor cubrimiento a los hechos que promovían cambios más radicales (Primavera Árabe) con técnicas más dramáticas, muy por encima de los movimientos indignados que perseguían reformas más moderadas y sus acciones no merecían tal atención.

\section{Bibliografía}

\section{Referencias bibliográficas}

Álvarez-Ossorio, I. (2011). Siria ante la revuelta: el blindaje del régimen. Real Instituto Elcano (ARI).

Baldwin, R. (November de 1997). The causes of regionalism. The World Economy, 20, pp. 865-888.

Benkirane, R. (2012). The Alchemy of Revolution: The Role of Social Networks and New Media in the Arab Spring. GCSP Policy Paper, 7.

Bennet, W., $\&$ Segerberg, A. (Junio de 2012). The logic of connective action. Information, Communication E Society, 15 (5), pp. 739-768.

Castells, M. (2012). Autocomunicación de masas y movimientos sociales en la era de internet. En S. Aguilar, Anuari del conflicte social 2011 (pp. 11-19). Barcelona: Universidad de Barcelona.

Chan, J. M., E Lee, C. C. (1984). The journalistic paradigm on civil protests: A case study of Hong Kong. In A. Arno, \& W. Dissanayake, The news media in national and international conflict (pp. 183-202). Boulder, CO: Westview.

Cohen, S. (1980). Folk devils and moral panics: The creation of the mods and rockers. Oxford, UK: Blackwell.

Comunello, F., E Anzera, G. (2012). Will the revolution be tweeted? A conceptual framework for understanding the social media and the Arab Spring.Islam and Christian-Muslim Relations, 23(4), pp. $453-470$.

Della Porta, D., E Diani, M. (2011). Los Movimientos Sociales. Madrid: Editorial Complutense. 
Eisenhower, D. (7 de Abril de 1954). The President's News Conference. The American Presidency Project. Recuperado de http://www.presidency.ucsb.edu/ws/?pid=10202

Eltantawy, N., \& Wiest, J. B. (2011). The Arab Spring Social Media in the Egyptian Revolution: Reconsidering Resource Mobilization Theory. International Journal of Communication, 5, 18.

Entman, R. M. (1993). Framing: Toward a clarification of a fractured paradigm. Journal of Communication, 43(4), pp. 51-58.

Esparcia, A. C., Ponce, D. G., E Lozano, E. S. (2013). Movimientos sociales y estrategias de comunicación. El caso del 15-M y de Occupy Wall Street. Estudios sobre el mensaje periodístico, 19(1), pp. 71-89.

Gamson, W. A. (1992). Talking politics. Cambridge, UK: Cambridge University Press.

Gamson, W., E Modigliani, A. (1989). Media Discourse and Public Opinion on Nuclear Power: A Constructionist Approach. American Journal of Sociology, 95(1), pp. 1-37.

García, A. P. (2011). La percepción del movimiento" 15-M" en las ediciones digitales de El Mundo y El País. Tejuelo: Didáctica de la Lengua y la Literatura. Educación, (12), pp. 196-217.

Gitlin, T. (1980). The whole world is watching: Mass media and the making and unmaking of the new left. Berkeley: University of California Press.

Goffman, E. (1974). Frame analysis: An essay on the organization of experience. New York: Harper E Row.

Hamdy, N. \& Gomaa, 2012: "Framing the Egyptian Uprising in Arabic Language Newspapers and Social Media". Journal of Communication, 62, pp. 195-211.

Hessel, S. (2010). Indignaos. Barcelona: Destino.

Khamis, S. (2011): "The Transformative Egyptian Media Landscape: Changes, Challenges and comparative Perspectives". International Journal of Communication, 5, pp. 1159-1177.

Khondker, H.H. (2011): "Role of the New Media in the Arab Spring". Globalizations, 8 (5), pp. 675-679.

Koopmans, R. (2007). Protest in time and space: the evolution of waves of contention. En D. Snow, S. Soule, $\mathcal{E}$ H. Kriesi (Edits.), The Blackwell companion to social movement (pp. 19-46). London: Blackwell.

Lafuente Pérez, P., \& Zugasti Azagra, R. (2012). La irrupción del 15-M: la cobertura en El País y en El Mundo.

Martí, S. (abril de 2004). Los movimientos sociales en un mundo globalizado: ¿alguna novedad? América Latina Hoy (36), pp. 79-100.

McLeod, D. (2007). News Coverage and Social Protest: How the Media's Protect Paradigm Exacerbates Social Conflict. Journal of Dispute Resolution. pp. 187-194.

McLeod, D. M., E Detenber, B. H. (1999). Framing effects of television news coverage of social protest. Journal of Communication, 49(3), pp. 3-23.

McLeod, D. M., \& Hertog, J. K. (1992). The manufacture of public opinion by reporters: Informal cues for public perceptions of protest groups. Discourse and Society, 3, pp. 259-275.

Pan, Z., E Kosicki, G. M. (1993). Framing analysis: An approach to news discourse. Political Communication, 10, pp. 55-75.

Rabbia, N. (julio-diciembre de 2012). La primavera árabe en el curso de la crisis financiera internacional. Estudios (28), pp. 115-128. 
Reese, S. D. (2007). The framing project: A bridging model for media research revisited. Journal of Communication, 57 (1), pp. 148-154.

Revista Time. (2011). The Protester. Time, Person of the year. Recuperado de: http://www.time.com/time/ person-of-the-year/2011

Shoemaker, P. J. (1984). Media treatment of deviant political groups. Journalism Quarterly (61), pp. 66-75.

Soria, M.M (2013): El tratamiento informativo de la Primavera Árabe: Libia y su papel en las portadas españolas, Revista Encuentros, Vol 11 (1), pp. 25-39.

Stepanova, E. (2011). The role of information communication technologies in the "arab spring". Ponars Eurasia, 15, pp. 1-6.

Tovar Ruiz, J. (Septiembre de 2011). ¿Entre la teoría y la práctica? cuatro momentos de la doctrina en la política exterior estadounidense. CIDOB d'afers internacionals (95), pp. 165-187.

Valenzuela, J. (2012). Crónica del nuevo Oriente Próximo. Madrid: Catarata.

Referencias hemerográficas

Abdahllah, R. (17 de Febrero de 2011). "Los árabes no soportan más represión". El Espectador, pág. 10.

AFP. (9 de Febrero de 201 la). Reavivan protestas en Egipto. El Tiempo, pág. 10.

AFP. (12 de Mayo de 201 lb). Multitudinarias protestas en Grecia por plan de austeridad. El Tiempo, pág. 11.

AFP. (16 de Mayo de 2011 c). Jóvenes reclaman un futuro. El Tiempo.

AFP. (16 de Junio de 2011 d). 'Primavera China'. El Espectador, pág. 16.

AFP. (16 de noviembre de 201 le). 'Indignados' de Nueva York, de plaza en plaza. El Tiempo, pág. 10.

Agencias. (21 de Marzo de 201 1). Marroquíes, yemeníes y sirios claman por libertad. El Tiempo, pág. 8.

Agencias. (21 de marzo de 201 lf). Marroquíes, yemeníes, y sirios claman por libertad. El Tiempo, pág. 8.

Álvarez, S. (14 de Agosto de 2011). La madre patria de los (indignados). El Tiempo, pág. 4.

Barrionuevo, A. (16 de Agosto de 2011). Con besos y cacerolas, chilenos piden reformas. El Espectador, pág. IV (NYT).

Bastenier, M. Á. (6 de Marzo de 2011). De reyes y presidentes. El Espectador, pág. 24.

Beris, J. (1 de Agosto de 2011). Miles de 'indignados' en Israel. El Tiempo, pág. 6.

Bloomberg. (15 de Octubre de 2011). Movimiento de los 'indigandos' se globaliza. El Tiempo, pág. 1.

Bonet, E. (13 de Febrero de 2011). Un pueblo que dio ejemplo de valor y resistencia de 18 días. El Tiempo, pág. 6.

Brat, I. (31 de Octubre de 2011). El rostro humano del desempleo en España. El Tiempo, pág. 29.

Bremer, I. (7 de Abril de 2011). Oriente Medio: gobiernos nuevos para problemas viejos. El Tiempo, pág. 19.

Castells, M. (29 de enero de 2011). La wikirrevolución del jazmín. LaVanguardia.es. Recuperado de http://www.lavanguardia.com/opinion/articulos/20110129/54107291983/la-wikirrevolucion-deljazmin.html 
De Vasconcelos, Á. (3 de Febrero de 2011). El rugir de la ola democrática. El Tiempo, pág. 22.

Dharmadeva. (11 de Octubre de 2011). Los ocupantes indignados. El Espectador, pág. 32.

EFE - AFP. (16 de Junio de 2011). El 15 M, violento en Barcelona. El Tiempo, pág. 6.

EFE. (21 de Mayo de 2011 a). Movimiento 15-M ya se extiende a varios países. El Tiempo, pág. 12.

EFE. (20 de Junio de 201 lb). 'Indignados' marchan en toda España. El Tiempo, pág. 9.

EFE. (22 de Julio de 201 lc). 'Indignados' reclaman por vivienda en Israel. El Tiempo, pág. 6.

EFE. (6 de Agosto de 201 ld). Se fortalece movimiento 'indignado' en España. El Tiempo, pág. 12.

EFE. (26 de septiembre de 201 le). Nueva York también tiene su movimiento 'indignado'. El Tiempo, pág. 9.

EFE. (15 de Octubre de 201 1f). Más de 960 ciudades se unen a los 'indignados'. El Tiempo, pág. 10.

EFE. (16 de Octubre de $2011 \mathrm{~g}$ ). Protesta global de los 'indignados'. El Tiempo, pág. 1.

El Espectador. (15 de Enero de 2011 a). Presidente de Túnez se marcha. El Espectador, pág. 10.

El Espectador. (29 de enero de 201 lb). Jordania también protesta. El Espectador, pág. 12.

El Espectador. (2 de febrero de 2011 c). Túnez, el efecto dominó. El Espectador.

El Espectador. (9 de Febrero de 2011 le). La encrucijada egipcia. El Espectador, pág. 20.

El Espectador. (18 de Febrero de 2011f). El mundo árabe se revoluciona. El Espectador, pág. 10.

El Espectador. (21 de Febrero de 201 lg). Libia: renovación o guerra. El Espectador, pág. 6.

El Espectador. (2 de marzo de 201 h). Choques, También en Irán. El Espectador, pág. 15.

El Espectador. (25 de marzo de 2011 i). Siria, miles de vocen en contra. El Espectador, pág. 12.

El Espectador. (22 de Mayo de 2011 j). Las protestas en el mundo. El Espectador, pág. 21.

El Espectador. (9 de agosto de 20111). Seis meses de primavera árabe. El Espectador, pág. 28.

El Espectador. (15 de Agosto de $2011 \mathrm{~m}$ ). El mundo al revés. El Espectador, pág. 36.

El Espectador. (11 de Octubre de 2011 lo). Aumenta la protesta. El Espectador, pág. 30.

El Espectador. (12 de Octubre de 201 1o). Más arrestos de manifestantes en EEUU. El Espectador, pág. 15.

El Espectador. (15 de Octubre de 2011 p). El día de los indignados. El Espectador, pág. 1.

El Espectador. (29 de octubre de 2011 q). Revueltas en la cuna de la Primavera Árabe. El Espectador, pág. 16.

El Espectador. (3 de Junio de 201 lq). Yemen, al borde de una guerra civil. El Espectador, pág. 9.

El Espectador. (10 de Noviembre de 201 1r). Reversazo a la reforma educativa. El Espectador, págs. 2-3.

El Espectador. (8 de Febrero de 2011 r). Un conflicto de intereses. El Espectador, pág. 9.

El Espectador. (25 de Noviembre de 201 1s). Marcha desde Chile hasta Colombia. El Espectador, pág. 6.

El Tiempo \& EFE. (3 de Abril de 2011). Bashar, el oftalmólogo de los brazos cruzados. El Tiempo, pág. 18.

El Tiempo. (15 de enero de 201 1a). Presión social tumba al gobierno de Túnez. El Tiempo, pág. 8.

El Tiempo. (2 de febrero de 2011 b). Tensa calma en Marruecos. El Tiempo. 
El Tiempo. (4 de Febrero de 2011 c). La ceniza de la esfinge. El Tiempo, pág. 17.

El Tiempo. (5 de febrero de 2011 d). Tres escenarios posibles de desenlace de la crisis en Egipto. El Tiempo, pág. 3.

El Tiempo. (12 de febrero de 2011 e). Egipto venció a la dictadura. El Tiempo, pág. 1.

El Tiempo. (23 de Junio de 2011 f). Hessel, Papá de 'los Indignados'. El Tiempo, pág. 1.

El Tiempo. (7 de Agosto de 201 g). 250 mil manifestantes 'indignados' en Israel. El Tiempo, pág. 19.

El Tiempo. (10 de Agosto de 201 1h). Un mundo de protestas. El Tiempo, pág. 18.

El Tiempo. (22 de Agosto de 201 1i). A una sola voz, Colombia pidió cese de la corrupción. El Tiempo, pág. 4.

El Tiempo. (9 de Noviembre de 2011 j). 'Desde los 70 no vivíamos algo así': vocero estudiantil. El Tiempo, pág. 8.

El Tiempo. (10 de noviembre de 201 1k). Colombianos también marchan hoy en Argentina. El Tiempo, pág. 2.

El Tiempo. (25 de Noviembre de 201 11). Esta vez, la marcha de jóvenes fue continental. El Tiempo, pág. 22.

ElMundo.es. (21 de octubre de 2012). Gadafi, muerto. ElMundo.es. Recuperado de http://www.elmundo. es/elmundo/2011/10/20/internacional/1319109552.html

Gómez, S. (9 de Octubre de 2011). Crece la fuerza 'indignados' en E.E.U.U. El Tiempo, pág. 20.

Gaviria, A. (13 de Noviembre de 2011). Voracidad. El Espectador, pág. 43.

Hessel, S. (23 de junio de 2011). El 'Padre' de los indignados. El Tiempo, pág. 19.

Hoyos, A. (2 de Febrero de 2011 ). La encrucijada egipcia. El Espectador, pág. 21.

López, Á. (23 de Junio de 2011). El 'padre' de los indignados. El Tiempo, pág. 19.

López, C. (21 de Julio de 2011). Chile protesta por lo que Colombia propone. El Tiempo, pág. 21.

Matador. (21 de octubre de 2011). Otro que Cae. El Tiempo.

Moffett, M., E Pica, C. (2 de Septiembre de 2011). La disparidad económica moviliza a Chile. El Tiempo, pág. 12.

Morales, F. (28 de septiembre de 2011). Los indignados fueron pocos. El Espectador, pág. 4.

Muñoz, A. (3 de Marzo de 2011). Lecciones desde Medio Oriente. El Espectador, pág. 30.

Muñoz, S. (16 de Agosto de 2011). De la utopía a la distopía. El Tiempo, pág. 23.

Naim, M. (11 de Diciembre de 2011). La voz de los 'Indignados'. El Tiempo, pág. 3.

Orduz, R. (15 de Febrero de 2011). Facebook en Egipto. El Espectador, pág. 24.

Ortega, I. (10 de Diciembre de 2011). De la Primavera Árabe al invierno ruso. El Espectador, pág. 17.

Ospina, W. (22 de Mayo de 2011). Democracia ya. El Espectador, pág. 52.

Pacheco, D. (4 de Octubre de 2011). Los desubicados de Wall Street. El Espectador, pág. 32.

Papeto. (2 de Febrero de 2011 ). Resignada inconformidad. El Tiempo , pág. 19. 
Peckel, M. (2 de febrero de 201 1a). Tsunami en Oriente Medio. El Espectador.

Peckel, M. (23 de Febrero de 201 lb). Las diferentes realidades del mundo árabe. El Espectador, pág. 12.

Pérez, A. (30 de Marzo de 2011). "Todos somos eternos". El Espectador, pág. 8.

Plá, F. (5 de Agosto de 2011). En Damasco, la tensión hace hablar en voz baja. El Tiempo, pág. 20.

Reuters. (15 de febrero de 201 la). Siria, otro Gobierno, pero mismo presidente. El Tiempo, pág. 10.

Reuters. (19 de Febrero de 201 lb). Más muertos por ola de protestas. El Tiempo, pág. 1.

Reuters. (16 de Octubre de 2011 c). La voz de protesta de los indignados se hace global. El Tiempo, pág. 14.

Rueda, M. (23 de Octubre de 2011). iQue vivan los estudiantes! El Tiempo, pág. 13.

Salgar, D. (15 de Octubre de 2011). Un mundo de indignados. El Espectador, pág. 12.

Samper, J. (7 de Agosto de 2011). La voz de los latinos 'indignados'. El Tiempo, pág. 16.

Sarmiento, E. (16 de Octubre de 2011). Inconformidad educativa. El Espectador.

Seligson, H. (26 de Julio de 2011). Rebeldes con futuro empresarial. El Espectador, pág. I (NYT).

Slackman, M. (29 de Marzo de 2011). La primavera árabe bajo los déspotas. El Espectador, pág. I (NYT).

Tickner, A. (16 de Noviembre de 2011). Juventud: ¿no futuro? El Espectador, pág. 16.

Uribe, N. (15 de Octubre de 2011). ¿Por qué protestan? El Espectador, pág. 31.

Vásquez, M. (16 de Mayo de 2011). 'Es una crisis sistémica'. El Tiempo, pág. 9.

Wolf, M. (27 de Febrero de 2011). ¿Por qué la juventud mundial se está rebelando? El Espectador, pág. 32. 